\title{
Effects of the combination of TRC105 and bevacizumab on endothelial cell biology
}

\author{
Yingmiao Liu • Hongyu Tian • Gerard C. Blobe • \\ Charles P. Theuer • Herbert I. Hurwitz • \\ Andrew B. Nixon
}

Received: 18 November 2013 / Accepted: 12 June 2014 / Published online: 5 July 2014

(C) The Author(s) 2014. This article is published with open access at Springerlink.com

\begin{abstract}
Summary Endoglin, or CD105, is a cell membrane glycoprotein that is overexpressed on proliferating endothelial cells (EC), including those found in malignancies and choroidal neovascularization. Endoglin mediates the transition from quiescent endothelium, characterized by the relatively dominant state of Smad 2/3 phosphorylation, to active angiogenesis by preferentially phosphorylating Smad $1 / 5 / 8$. The monoclonal antibody TRC105 binds endoglin with high avidity and is currently being tested in phase $1 \mathrm{~b}$ and phase 2 clinical trials. In this report, we evaluated the effects of TRC105 on primary human umbilical vascular endothelial cells (HUVEC) as a single agent and in combination with bevacizumab. As single agents, both TRC105 and bevacizumab efficiently blocked HUVEC tube formation, and the combination of both agents achieved even greater levels of inhibition. We further assessed the effects of each drug on various aspects of HUVEC function. While bevacizumab was observed to inhibit HUVEC viability in nutrient-limited medium, TRC105 had little effect on HUVEC viability, either alone or in combination with bevacizumab. Additionally, both drugs inhibited HUVEC migration and induced apoptosis. At the molecular level, TRC105 treatment of HUVEC lead to decreased Smad 1/5/8 phosphorylation in response to BMP-9, a primary ligand for endoglin. Together, these results indicate that TRC105 acts as an effective anti-angiogenic agent alone and in combination with bevacizumab.
\end{abstract}

Y. Liu $\cdot$ H. Tian $\cdot$ G. C. Blobe $\cdot$ H. I. Hurwitz $\cdot$ A. B. Nixon $(\bowtie)$

Department of Medicine, Duke University Medical Center,

Box 2631, Durham, NC 27710, USA

e-mail: anixon@duke.edu

C. P. Theuer

Tracon Pharmaceuticals, Inc., San Diego, CA 92121, USA
Keywords TRC105 $\cdot$ Endoglin $\cdot$ Bevacizumab · Angiogenesis $\cdot$ Endothelial cells

\section{Introduction}

Anti-angiogenic therapies have emerged as prominent approaches for cancer treatment over the past decade $[1,2]$. Tumor progression is heavily dependent on angiogenesis for primary tumor growth and metastasis. Anti-angiogenic agents inhibit an organism's potential to develop new blood vessels and prevent tumor growth by blocking access to oxygen and nutrients. Bevacizumab (Avastin ${ }^{\mathrm{TM}}$ ), the first approved antiangiogenic drug, binds vascular endothelial growth factor (VEGF) and was approved by Food and Drug Administration for the treatment of metastatic colorectal cancer in 2004 [3]. Bevacizumab is currently approved for multiple cancer indications, based on the prolongation of patient survival, clinically confirming the value of anti-angiogenic therapeutics which target the VEGF pathway [4].

Despite the widespread use of anti-angiogenic agents, the clinical benefit is limited and transient [5]. Such therapies appear to benefit a subset of cancer patients; and those who respond ultimately progress. This phenomenon is not surprising given that angiogenesis is regulated through a complex interplay of multiple pathways. When VEGF-mediated signaling is blocked by bevacizumab, other angiogenic pathways are activated, resulting in drug resistance. Therefore, combining drugs that target different angiogenic pathways may be a more effective strategy. Currently, more than forty antiangiogenic drugs are being tested in clinical trials [6].

Endoglin is a homodimeric transmembrane glycoprotein highly expressed on proliferating endothelial cells [7, 8]. As a co-receptor for TGF- $\beta$ and for bone morphogenic protein (BMP), endoglin associates with ALK1, an endothelial cellspecific type-I receptor, to promote downstream Smad 1/5/8 
phosphorylation and endothelial cell proliferation, primarily in response to BMP [9]. Recent data by Nolan-Stevaux et al. strongly supports that endoglin-dependent BMP signaling is the critical pathway for Smad $1 / 5 / 8$ activation in primary HUVEC cells [10]. In contrast, in the absence of endoglin, another type-I receptor, ALK5, promotes downstream Smad $2 / 3$ phosphorylation that maintains a state of EC quiescence. This balance between Smad 1/5/8 and Smad 2/3 phosphorylation regulates EC homeostasis [11]. When Smad 1/5/8 signaling predominates, EC undergo proliferation, migration, and promote angiogenesis; when Smad 2/3 signaling predominates, EC remain quiescent. Consistent with its angiogenic role, endoglin is markedly upregulated on the endothelium of malignancies [8]. Dense staining of endoglin has been observed in the angiogenic blood vessels of more than 10 types of tumor tissues and correlated with poor prognosis [12, 13], suggesting its potential as a target for clinical intervention [14].

TRC105 is a monoclonal antibody that binds endoglin with high avidity and is currently being evaluated in phase $1 \mathrm{~b}$ and phase 2 clinical trials [15]. TRC105 exhibited promising safety and activity in the first-in-human, phase 1 trial [16]. The phase 1, dose escalation study determined the recommended dose for phase 2 to be $10 \mathrm{mg} / \mathrm{kg}$ weekly, or $15 \mathrm{mg} / \mathrm{kg}$ every two weeks. Both doses resulted in high circulating TRC105 levels in patients plasma, with peak concentrations ranging from 200 to $600 \mu \mathrm{g} / \mathrm{ml}$ [16].

Due to the fact that TRC105 targets an essential angiogenic pathway distinct from the VEGF pathway targeted by bevacizumab, the combination of both drugs may provide greater activity. In this study, we tested the effects of TRC105 and bevacizumab as single agents, as well as in combination, on EC tube formation, viability, migration, and apoptosis. Further, we assessed the effects of TRC105 on patterns of Smad phosphorylation in HUVEC cells.

\section{Materials and methods}

\section{Cell culture}

Low passage HUVEC cells were purchased from Clonetics/ Lonza (Walkersville, MD). HUVEC were cultured in either regular medium containing EBM-2 basic medium supplemented with EGM-2 MV single aliquots; or nutrientlimited medium containing EBM-2 basic medium supplemented with $0.5 \% \mathrm{FBS}$ and $30 \mathrm{ng} / \mathrm{ml} \mathrm{VEGF} \mathrm{(Lonza,}$ Walkersville, MD). All cells were maintained in a $37{ }^{\circ} \mathrm{C}, 5 \% \mathrm{CO}_{2}$ incubator. TRC105 (5 mg/ml) was provided by Tracon Pharmaceuticals, Inc. (San Diego, CA). Bevacizumab (25 mg/ml) was from Genentech Inc. (San Francisco, CA).

\section{HUVEC tube formation}

HUVEC were pre-treated with $100 \mu \mathrm{g} / \mathrm{ml} \mathrm{TRC105,} 100 \mathrm{ng} / \mathrm{ml}$ bevacizumab, or both drugs for $8 \mathrm{~h}$ in regular medium. Human IgG (Jackson Immuno Research, West Grove, PA) was used as an isotype control. The cells were harvested and maintained in drug containing medium, and $1.5 \times 10^{4}$ HUVEC were inoculated onto pre-polymerized ECMatrix gel (In vitro angiogenesis assay kit, Chemicon, Temecula, CA). After $16 \mathrm{~h}$ incubation, cells were visualized using the Axiobserver in the Duke Light Microscopy Core facility (LMCF). Closed polygons were counted, and total tube length measured with the MetaMorph software (MDS Analytical Technologies, Sunnyvale, CA).

\section{HUVEC viability (MTS assay)}

HUVEC were inoculated at 5,000 cell/well onto a 96-well plate. After overnight incubation, cells were treated with either regular or limited medium containing either TRC105, bevacizumab, the combination of both drugs, or IgG control for $72 \mathrm{~h}$ with daily medium change. At the termination of the assay, $20 \mu \mathrm{l}$ MTS tetrazolium compound (CellTiter 96 Aqueous One Solution Cell Proliferation Assay, Promega, Madison, WI) was added to each well, absorbance at $490 \mathrm{~nm}$ was recorded $4 \mathrm{~h}$ later following the manufacturer's protocol.

\section{HUVEC migration}

HUVEC $\left(8 \times 10^{5} /\right.$ well $)$ were inoculated onto a 6 -well plate. After a confluent monolayer had formed overnight, a scratch was introduced with a sterile $200 \mu$ tip. Cell debris was removed by washing with $\mathrm{PBS}$, fresh regular medium containing either IgG isotype control $(100 \mu \mathrm{g} / \mathrm{ml})$, TRC105 $(100 \mu \mathrm{g} / \mathrm{ml})$, bevacizumab $(100 \mathrm{ng} / \mathrm{ml})$, or the combination of TRC105 $(100 \mu \mathrm{g} / \mathrm{ml})$ and bevacizumab (100 ng/ml) was supplied. Scratch filling was monitored using a live cell station in Duke LMCF over a period of $16 \mathrm{~h}$. Percentage of scratch filling was calculated as (Distance between gap edges at time point 0 - distance at time point $\mathrm{X}$ )/distance at time point $0 * 100 \%$, using MetaMorph software.

\section{HUVEC apoptosis}

HUVEC $\left(1 \times 10^{5} /\right.$ well $)$ were inoculated onto a 6 -well plate in which a gelatin-coated glass slide had been placed at the bottom. HUVEC were maintained in regular or limited medium with TRC105, bevacizumab, or the combination of both for $72 \mathrm{~h}$. Fresh medium with drugs were applied daily. Cells were then fixed in methanol: acetic acid $(3: 1)$ for $5 \mathrm{~min}$ at $4{ }^{\circ} \mathrm{C}$, washed three times with PBS, and stained with Hoechst 33,342 (5 $\mathrm{gg} / \mathrm{ml}$, Calbiochem, La Jolla, CA) for $10 \mathrm{~min}$ at 
room temperature. Then cells were washed three more times, the slides removed from plate wells, and mounted onto a glass carrier with Vectashield mounting medium for fluorescence (Vector Laboratories, Inc., Burlingame, CA). Apoptotic nuclei were visualized under a fluorescence microscope in Duke LMCF. Ten representative fields were imaged, cells counted, and the ratio of apoptotic nuclei vs. total nuclei was calculated with MetaMorph software.

Smad signaling in HUVEC

$\operatorname{HUVEC}\left(5 \times 10^{5} /\right.$ well $)$ were inoculated onto a 6 -well plate and incubated overnight. Cells were serum starved in EBM-2, $0.1 \% \mathrm{BSA}$, and $10 \mathrm{mM}$ Hepes for $4 \mathrm{~h}$. Cells were pretreated with TRC105 or isotype control for $1 \mathrm{~h}$, and stimulated with $0.2 \mathrm{ng} / \mathrm{ml}$ BMP-9, or $0.25 \mathrm{ng} / \mathrm{ml}$ TGF- $\beta 1$ (R\&D systems, Minneapolis, MN) for $1 \mathrm{~h}$. Then cells were put on ice immediately, cell lysate harvested in lysis buffer: $20 \mathrm{mM}$ Hepes, $2 \mathrm{mM} \mathrm{MgCl} 2,1 \mathrm{mM}$ EDTA and EGTA, $150 \mathrm{mM} \mathrm{NaCl}, 1 \%$ Triton X-100, $0.1 \%$ SDS, and protease inhibitors. After centrifugation at $16,000 \times \mathrm{g}$ for $10 \mathrm{~min}$, cell debris and nuclei were removed, and cell lysates were snap frozen before stored at $-80^{\circ} \mathrm{C}$ freezer.

\section{Western immunoblots}

Cell lysates $(10 \mu \mathrm{g})$ were separated on a 4-20 \% SDS-PAGE gel. Blots were incubated with rabbit-anti-phos-Smad $1 / 5 / 8$, anti-Smad 1, anti-Phos-Smad2, or anti-Smad 2/3 (Cell Signaling, Danvers, MA), as well as mouse anti- $\beta$-actin for loading control, overnight at $4{ }^{\circ} \mathrm{C}$. LI-COR specific goat antirabbit, or goat anti-mouse IgG secondary antibody $(1: 5,000)$ was added and incubated for $1 \mathrm{~h}$ at room temperature. Immunoblots were analyzed using the Odyssey imaging system (LI-COR Biotechnology, Lincoln, NE).

\section{Results}

TRC105 and bevacizumab inhibit HUVEC tube formation

To evaluate the anti-angiogenic function of TRC105, HUVEC tube formation was first tested. Since TRC105 is a chimeric antibody cloned into an IgG1 backbone, human IgG molecule was used as an isotype control. As shown in Fig. 1a, overnight incubation of HUVEC with IgG control $(100 \mu \mathrm{g} / \mathrm{ml})$ on a matrigel leads to the development of extensive tubular networks, which can be quantified by counting the number of closed polygons and total length of capillary tubes. TRC105 $(100 \mu \mathrm{g} / \mathrm{ml})$ and bevacizumab $(100 \mathrm{ng} / \mathrm{ml})$ treated cells showed impaired tube formation, exhibited by less dense tube network and some disrupted regions. Strikingly, when
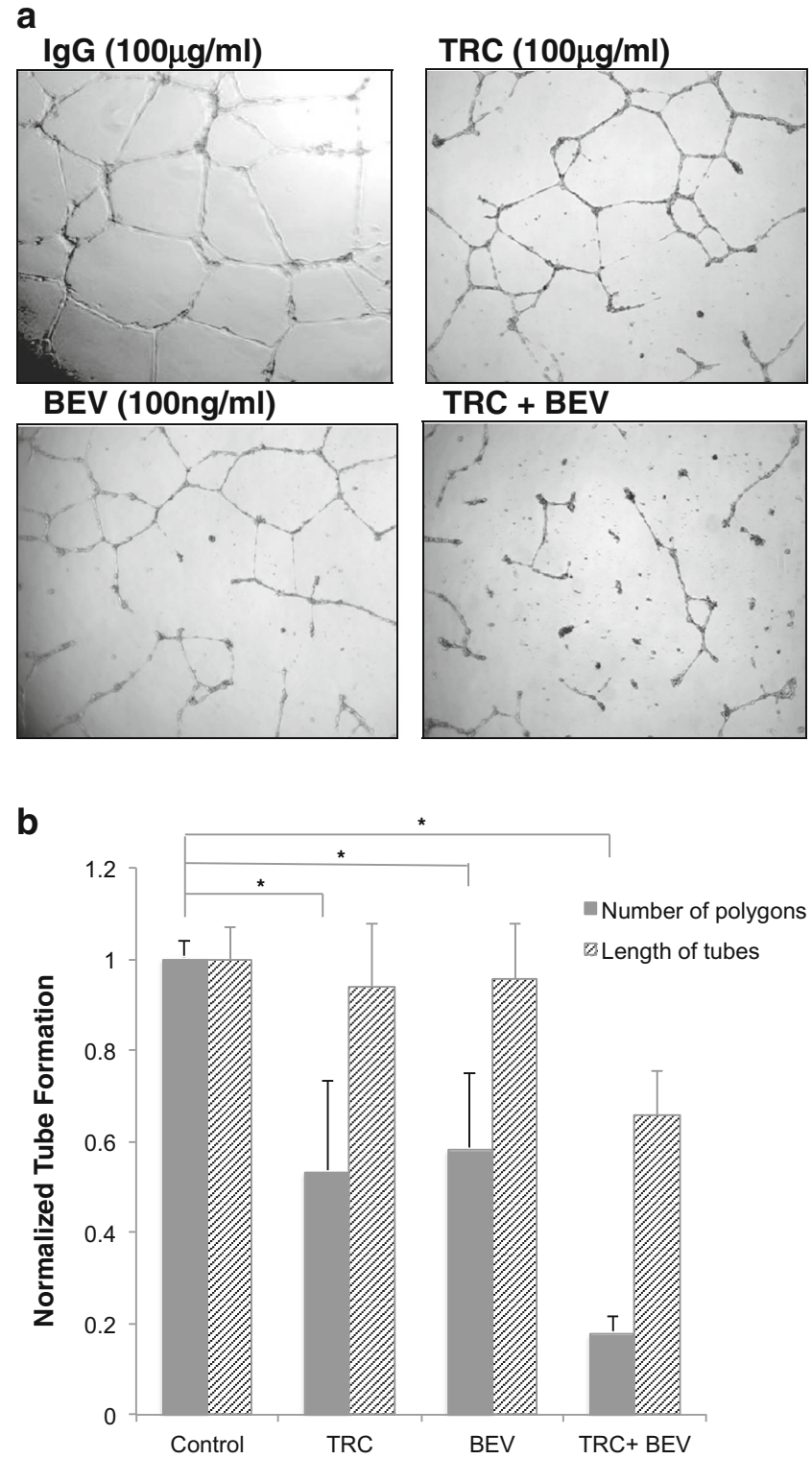

Fig. 1 TRC105 and bevacizumab inhibit HUVEC tubular network formation in in vitro angiogenesis assays. a. HUVEC cells growing on matrigel overnight in the presence of IgG control $(100 \mu \mathrm{g} / \mathrm{ml})$ formed extensive tube networks. TRC105 $(100 \mu \mathrm{g} / \mathrm{ml})$, bevacizumab $(100 \mathrm{ng} / \mathrm{ml})$, or the combination of both drugs was added and the effects on polygon formation and tube length were visualized. b. Normalized bar graph showing the fold inhibition on polygon formation and tube length. Each column represents the mean $\pm \mathrm{SD}$ of three independent experiments. ${ }^{*} p<0.05$ compared to IgG control

cells were treated with both agents, only partially formed tubes and fewer closed polygons could be detected. After data normalization, polygon formation was inhibited by $40-50 \%$ using either drug alone and by more than $80 \%$ using the combination of both drugs. The combination of drugs is significantly more effective in inhibiting polygon formation than either drug used alone ( $p \leq 0.05 ;$ Fig. 1b). The total length of tubes, an earlier biologic step reflecting mainly cell migration and alignment, was less affected, exhibiting 5-10\% 
inhibition from each drug alone, and more than $30 \%$ inhibition using the combination of drugs. Overall, these results indicate that both TRC105 and bevacizumab inhibit EC tube formation, and that the combination of drugs achieved more robust inhibition than either drug alone.

\section{Effect of TRC105 and bevacizumab on HUVEC viability}

Since EC tube formation is a comprehensive assay reflecting multiple cellular processes such as proliferation, migration/ alignment, and apoptosis, we further examined each functional aspect individually. To evaluate cell viability, HUVEC were treated with increasing concentrations of drug or isotype control for $72 \mathrm{~h}$, followed by the addition of the MTS tetrazolium compound, which undergoes a color change when bioreduced by metabolically active cells. While little to no effect of $\operatorname{IgG}$ was observed at the $\mathrm{ng} / \mathrm{ml}$ range (data not shown), IgG at the $\mu \mathrm{g} / \mathrm{ml}$ range inhibited HUVEC viability. At this dose range, TRC105 $(\mu \mathrm{g} / \mathrm{ml})$ elicited comparable inhibition to $\operatorname{IgG}(\mu \mathrm{g} /$ $\mathrm{ml}$ ) alone, suggesting the inhibition observed in response to TRC105 was an IgG non-specific effect. In regular medium, bevacizumab showed no appreciable inhibition on HUVEC viability when tested at concentrations of $100 \mathrm{ng} / \mathrm{ml}$ to $1 \mu \mathrm{g} / \mathrm{ml}$ (Fig. 2a). Higher concentrations of bevacizumab $(100 \mu \mathrm{g} / \mathrm{ml}$ to $1 \mathrm{mg} / \mathrm{ml})$ were also tested, but again, the effects were negligible (data not shown). When both drugs were combined, the inhibitory effect on HUVEC viability was essentially the same as IgG alone.

The lack of a bevacizumab effect on HUVEC viability in serum-containing medium was not surprising. The high abundance of growth factors present in the serum-containing medium, including FGF, EGF, VEGF, and IGF, all can serve as potential compensatory factors upon VEGF blockage. To isolate the effect of TRC105 and bevacizumab on VEGFspecific cell viability, we optimized a nutrient-limited medium that excluded all other growth factors (i.e., FGF, EGF, and IGF) except VEGF. Limited medium was formulated containing $0.5 \% \mathrm{FBS}$ and $30 \mathrm{ng} / \mathrm{ml} \mathrm{VEGF}$. In this setting, bevacizumab produced a significant drug-specific dosedependent inhibition on HUVEC viability ( $p<0.01$ vs. IgG control, Fig. 2b), while TRC105-mediated inhibition at $\mu \mathrm{g} / \mathrm{ml}$ concentrations was less robust and non-specific. A closer comparison among bevacizumab alone, bevacizumab $+\mathrm{IgG}$, bevacizumab + TRC105 treated cells revealed little enhancement when TRC105 was added to bevacizumab. Therefore, the combination of both drugs did not lead to greater inhibition of HUVEC viability as compared to bevacizumab alone.

\section{TRC105 and bevacizumab inhibit HUVEC migration}

The in vitro scratch assay was used to measure cell motility [17]. HUVEC cells were allowed to grow to confluence, then a gap was introduced into the cell monolayer and the process of cell migration was monitored over a period of $16 \mathrm{~h}$. In regular medium, untreated cells refilled the gap within 10 $11 \mathrm{~h}$. As shown in Fig. 3, incubation of HUVEC in the presence of $100 \mu \mathrm{g} / \mathrm{ml} \mathrm{TRC105}$ significantly delayed endothelial cell migration $(p<0.05)$. Treatment with $100 \mathrm{ng} / \mathrm{ml}$ bevacizumab achieved similar effects $(p<0.01)$. Treatment with both drugs inhibited migration more than observed with either TRC105 or bevacizumab alone $(p \leq 0.01)$ (Fig. 3). IgG isotype control at $100 \mu \mathrm{g} / \mathrm{ml}$ showed no inhibition on HUVEC migration (data not shown). When scratch filling was assessed in limited medium, HUVEC cells did not migrate well and never reached confluence in the absence of drugs, even after $24 \mathrm{~h}$ post scratch.
Fig. 2 Effect of TRC105 and bevacizumab on HUVEC viability. Subconfluent HUVEC were subjected to TRC105 (100$1,000 \mu \mathrm{g} / \mathrm{ml})$, bevacizumab $(100-1,000 \mathrm{ng} / \mathrm{ml})$, both drugs, or $\operatorname{IgG}(100-1,000 \mu \mathrm{g} / \mathrm{ml})$ treatment for 3 days in regular medium (a) and limited medium (b). Cell viability was measured by MTS tetrazolium assay, and absorbance at $490 \mathrm{~nm}$ was reported. Data represent the mean $\pm \mathrm{SD}$ of three independent experiments. $* *$ $p<0.01$ compared to IgG control a

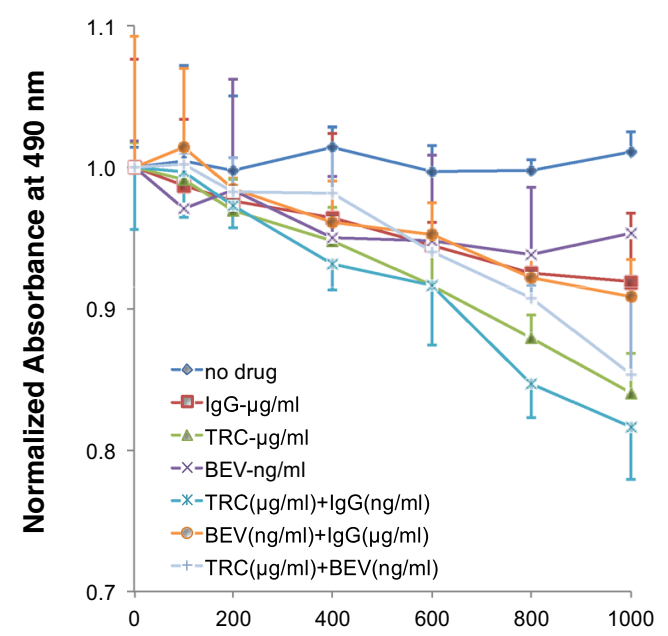

b

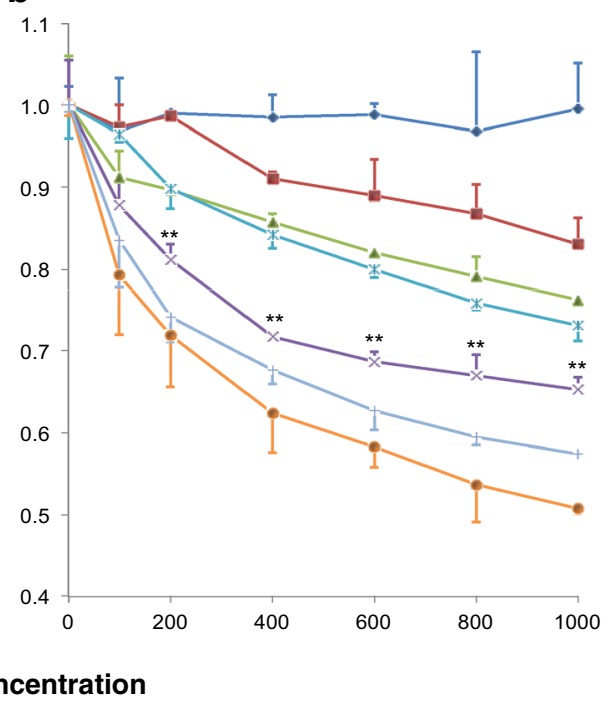




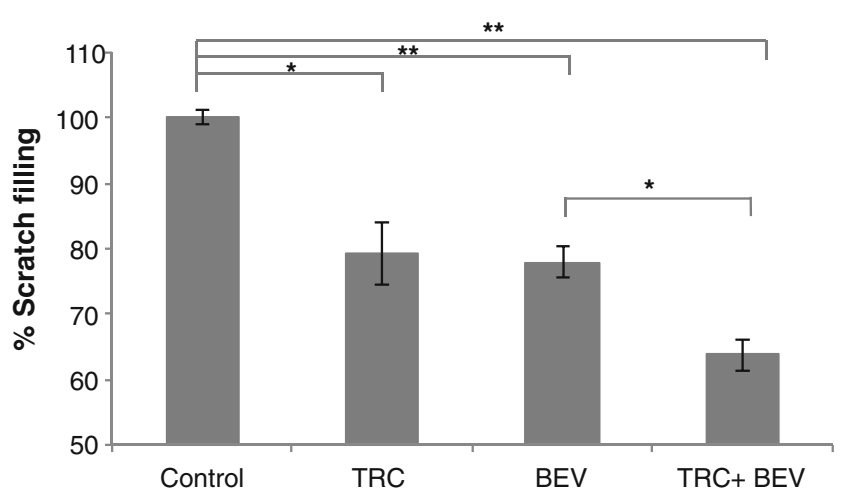

Fig. 3 TRC105 and bevacizumab inhibit HUVEC migration. HUVEC confluent monolayers were scratched to create a gap, exposed to TRC105 $(100 \mu \mathrm{g} / \mathrm{ml})$, bevacizumab $(100 \mathrm{ng} / \mathrm{ml})$, or the combination of TRC105 $(100 \mu \mathrm{g} / \mathrm{ml})$ and bevacizumab $(100 \mathrm{ng} / \mathrm{ml})$, and monitored for cell migration for $16 \mathrm{~h}$. Percentage of scratch filling at $10 \mathrm{~h}$ post scratch was shown. Each column represents the mean $\pm \mathrm{SD}$ of three independent experiments. $* p<0.05 ; * * p<0.01$ compared to no drug control

\section{TRC105 and bevacizumab induce HUVEC apoptosis}

To test the apoptotic effects of TRC105 and bevacizumab, HUVEC were first treated with each drug individually in regular or limited medium for $72 \mathrm{~h}$, and then subjected to Hoechst staining (Fig. 4). Condensed, fragmented nuclei representing apoptotic features were counted, and the ratio of apoptotic nuclei vs. total nuclei was plotted. Camptothecin $(4 \mu \mathrm{g} / \mathrm{ml})$ was used as a positive control and induced more than a 30 -fold increase in the apoptotic cell ratio after overnight incubation (data not shown). IgG isotype control was indistinguishable from the no drug control (data not shown) [18]. In regular medium, TRC105 exhibited a small, yet significant, dose-dependent induction of apoptosis, with a 3 -fold increase at $100 \mu \mathrm{g} / \mathrm{ml}$, and a 6-fold increase at $1,000 \mu \mathrm{g} / \mathrm{ml}$, versus no-drug control (Fig. 4a). Bevacizumab induced apoptosis to similar levels as seen with TRC105 ( $p<0.01$ vs. control). Additive effects were not observed when the drugs were combined, as the induction of apoptosis was similar compared to either single agent.

In limited medium, the basal apoptosis rate was higher than that in regular medium ( $5 \%$ vs. $1.2 \%$ ). TRC105 elicited a 2fold induction of apoptosis at $1,000 \mu \mathrm{g} / \mathrm{ml}$. Bevacizumab was a more potent inducer of apoptosis under these conditions, achieving a 3.8 fold increase at $1,000 \mathrm{ng} / \mathrm{ml}(p<0.001$ vs. control). As was seen with regular medium, the combination of drugs in limited medium did not further increase apoptosis (Fig. 4b).

TRC105 differentially modulates Smad 1/5/8 and Smad 2/3 signaling pathways in response to BMP-9 and TGF- $\beta 1$

Multiple factors have been identified as endoglin ligands, including TGF- $\beta 1$ and TGF- $\beta 3$ [7], as well as BMP-9 and
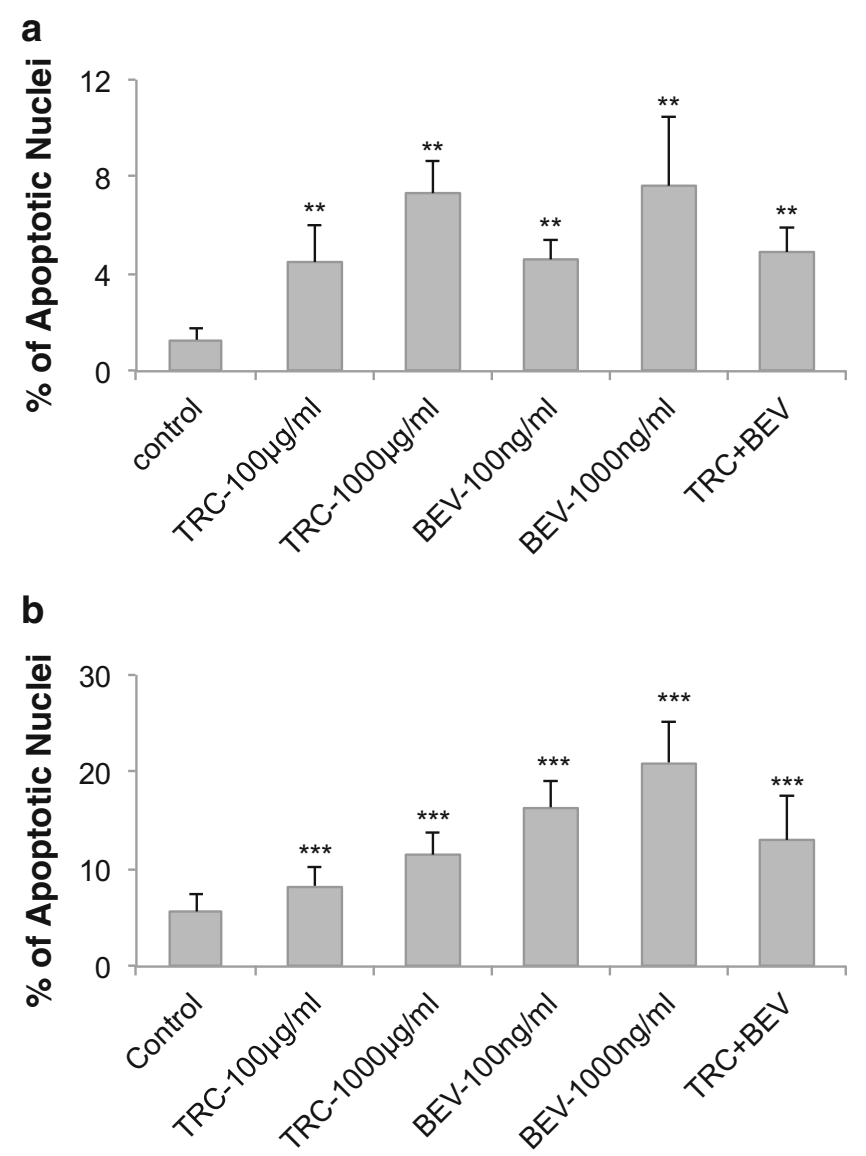

Fig. 4 TRC105 and bevacizumab induce HUVEC apoptosis. Apoptosis was evaluated by Hoechst staining after HUVEC were treated with TRC105 (100 or $1,000 \mu \mathrm{g} / \mathrm{ml})$, bevacizumab (100 or $1,000 \mathrm{ng} / \mathrm{ml})$, or the combination of drugs at the lower doses $(100 \mu \mathrm{g} / \mathrm{ml} \mathrm{TRC105}$ and $100 \mathrm{ng} / \mathrm{ml}$ bevacizumab) for 3 days. a. Regular medium. b. Limited medium. Each column represents the mean $\pm \mathrm{SD}$ of three independent experiments. ${ }^{* *} p<0.01, * * * p<0.001$ compared to no drug control

BMP-10 [19]. To investigate these signaling modalities, serum-starved HUVEC cells were exposed to either BMP-9 or TGF- $\beta 1$. As shown in Fig. 5, BMP-9 strongly activated Smad 1/5/8 phosphorylation ( $\sim 30$ fold), but had little effect on Smad 2. In contrast, TGF- $\beta 1$ exposure mainly activated Smad 2 phosphorylation ( $\sim 5$ fold), but not Smad 1/5/8 signaling.

To explore the underlying molecular mechanisms contributing to the effects of TRC105 on HUVEC function, the phosphorylation status of Smad 1/5/8 and Smad 2 was investigated. When HUVEC were pre-incubated with increasing amounts of TRC105, BMP-9-induced Smad 1/5/8 phosphorylation was inhibited across all doses of TRC105 tested (Fig. 5, panel b), including a dose of $0.2 \mu \mathrm{g} / \mathrm{mL}$, which is the TRC105 concentration expected, based on binding avidity studies, to saturate endoglin binding sites on HUVECs. In contrast, TRC105 treatment only marginally modulated TGF- $\beta 1$ induced Smad 2 phosphorylation (panel C). Both isotype control $\operatorname{IgG}$ and bevacizumab exhibited negligible 

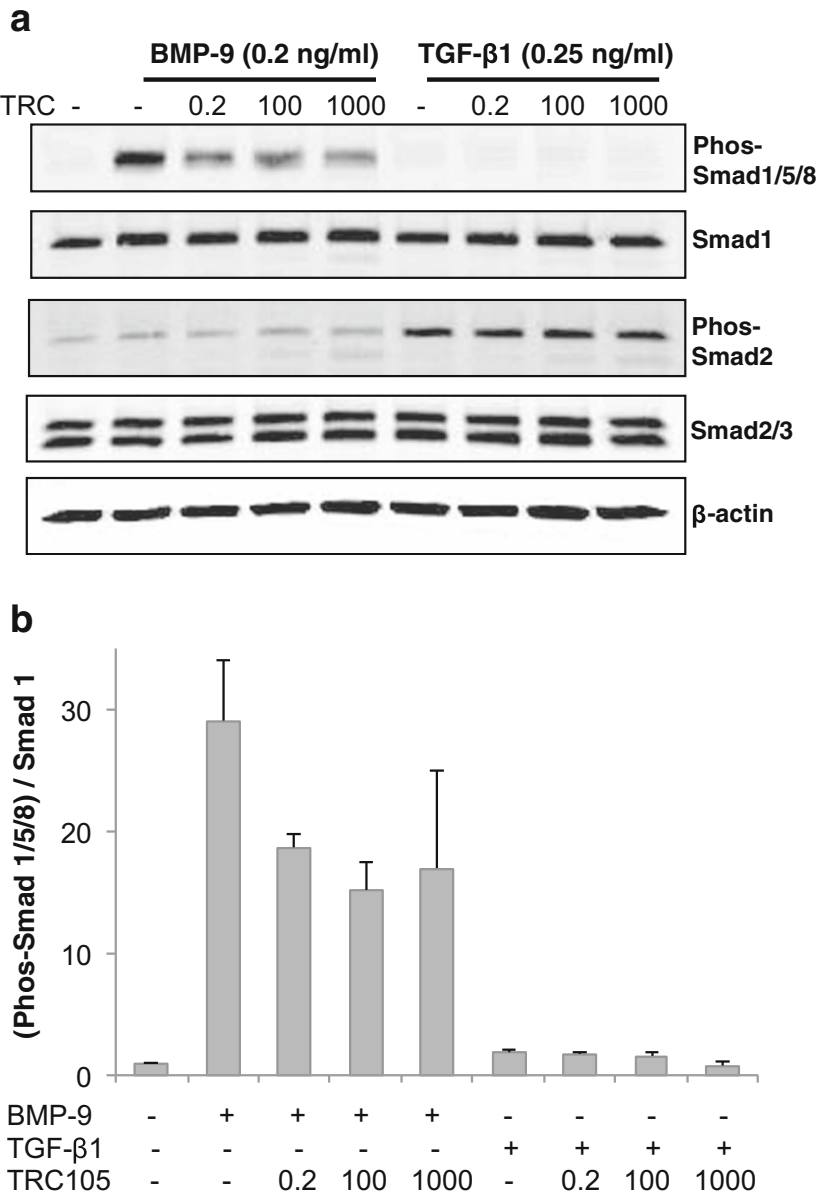

C

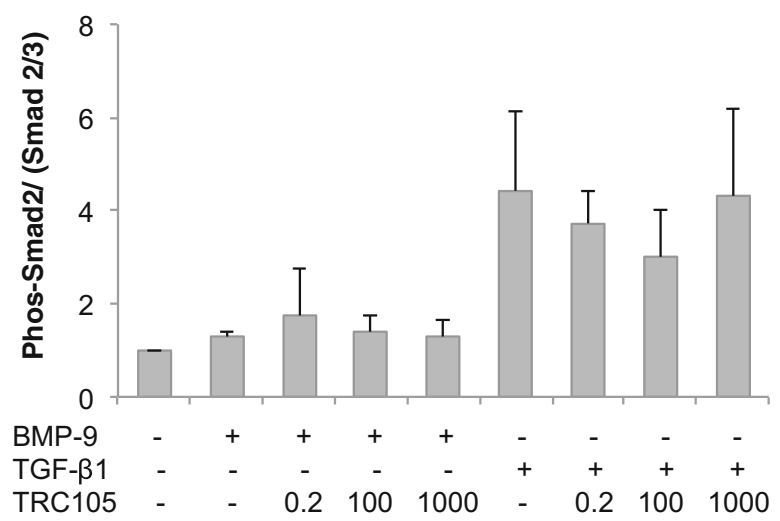

Fig. 5 TRC105 diminished BMP-9 induced Smad 1/5/8 signaling in HUVEC cells. a. Western blotting showing the levels of phosphorylated Smad 1/5/8, total Smad 1, phos-Smad 2, total Smad 2/3 in response to the stimulation of BMP-9 or TGF- $\beta 1$. Cells were pre-incubated with various doses of TRC105 for $1 \mathrm{~h}$ prior to stimulation. b. Effect on Smad 1/5/8 signaling as revealed by the ratio of phos-Smad $1 / 5 / 8$ vs. total Smad 1. c. Effect on Smad 2 signaling as revealed by the ratio of phos-Smad 2 vs. total Smad 2/3. 0.2, 100, 1,000 depict TRC105 doses of 0.2, 100, and $1,000 \mu \mathrm{g} / \mathrm{ml}$, respectively

inhibition of either Smad 1/5/8 or Smad 2 phosphorylation (data not shown).

\section{Discussion}

In this study, we evaluated the anti-angiogenic drug TRC105, and its combination with bevacizumab, in a series of HUVEC functional assays. Initially, individual drugs were tested over a broad range of dosing levels under each assay condition. In every assay system, doses that induced moderate effects (typically around $25-30 \%$ inhibition) were chosen for these analyses in order to detect potential additive or synergistic effects with both drugs. For most assays, the dose of TRC105 was empirically determined to be $100 \mu \mathrm{g} / \mathrm{ml}$, as lower doses exhibited little effect on HUVEC function. This dose is clinically relevant as pharmacokinetic analyses revealed that the serum concentration of TRC105 following dosing in advanced cancer patients at the recommended phase 2 dose ranged from 200 to $600 \mu \mathrm{g} / \mathrm{ml}$ [16]. For bevacizumab, the dose tested in most assays was empirically determined to be $100 \mathrm{ng} / \mathrm{ml}$.

Despite the fact that TRC105 and bevacizumab are both monoclonal antibodies that block angiogenesis, the targets of each drug are different and utilize distinct mechanisms. Endoglin is an integral cell membrane receptor located on proliferating endothelial cells [20], whereas VEGF is a soluble angiogenic factor that is primarily released by tumor cells and tumor-associated stromal cells [21, 22]. Therefore, combining TRC105 and bevacizumab has the potential to block complementary pathways leading to improved efficacy.

We observed that individually, both TRC105 and bevacizumab blocked HUVEC tube formation, and the most robust inhibition was achieved when both drugs were combined (Fig. 1). The tube formation assay is a powerful tool to monitor ECs during vascular network formation, representing an end-point evaluation of the complicated interplay among many processes, including proliferation, differentiation, migration, apoptosis, etc. To further interrogate these processes, we next investigated specific EC functional biology in more defined assay systems.

When given at $100-1,000 \mu \mathrm{g} / \mathrm{ml}$ levels, TRC105 and its isotype control (IgG) similarly inhibited HUVEC viability, in both regular and nutrient-limited medium (Fig. 2). In contrast, although bevacizumab elicited little effect on HUVEC viability in regular medium, it showed dose-dependent, drugspecific inhibition in limited medium (Fig. 2b). While TRC105 had little effect on HUVEC viability, several observations are noteworthy. First, contrary to bevacizumab, TRC105 elicited no inhibitory effect on HUVEC growth in nutrient-limited medium. Second, given that the steady state plasma concentration of TRC105 in patients is in $\mu \mathrm{g} / \mathrm{ml}$ range, the potential non-specific effect of IgG on EC growth should be considered. Third, Anderberg et al., reported that genetic knockdown of endoglin sensitizes tumors to VEGF inhibition [23], advocating for the potential benefit of co-administration of these drugs. The underlying mechanism is unlikely to be an 
effect on EC growth/viability, as suggested by our MTS data and suggests that the inhibition of HUVEC tube formation is not due to the impact of these agents on cell viability.

The effect of endoglin on cell motility is controversial. While endoglin is considered to be an inhibitor of cell migration through its extracellular RGD domain that binds to intercellular matrix proteins [24], evidence exists that endoglin promotes ALK1 signaling, leading to increased cell mobility [25]. Additionally, endoglin has been shown to antagonize the inhibitory effect of TGF- $\beta 1$ on HUVEC migration, suggesting a positive role of endoglin in HUVEC motility [26]. Our scratch assay data support the latter hypothesis (Fig. 3). TRC105 moderately decreased HUVEC migration, as quantified by a reduced percentage of cells that migrated into the gap created by the scratch. Bevacizumab exhibited similar inhibitory effects, consistent with VEGF's motilitypromoting role [27]. The combination of both drugs exhibited an additive inhibition when compared to either drug alone in the scratch filling assay.

EC apoptosis provided another opportunity to evaluate TRC105 and bevacizumab in both regular and limited medium. In the presence of multiple growth factors, TRC105 and bevacizumab exhibited similar potency in inducing HUVEC apoptosis (Fig. 4a). In limited medium, where VEGF is essentially the only growth factor, TRC105 was also active and exhibited dose-dependent induction of HUVEC apoptosis (Fig. 4b). These findings are in agreement with previous observations that SN6j, the parent antibody of TRC105, also led to increased HUVEC apoptosis in vitro [18]. However, there were no additive effects by combining both drugs.

Lastly, we explored the molecular mechanisms underlying the ability of TRC105 to block HUVEC function. Since endoglin is a type III receptor for TGF- $\beta$ and BMP, we investigated the effects of TRC105 on Smad signaling, pathways known to play pivotal roles in EC proliferation and viability. In assessing Smad phosphorylation (Fig. 5), three doses of TRC105 were chosen: $0.2,100$, and 1,000 $\mu \mathrm{g} / \mathrm{ml}$. A dose of $0.2 \mu \mathrm{g} / \mathrm{ml}$ is the target concentration predicted to saturate endoglin on cell surface [16]. Doses of 100 and $1,000 \mu \mathrm{g} / \mathrm{ml}$ fall within or close to the range of TRC105 plasma concentrations $(200-600 \mu \mathrm{g} / \mathrm{ml})$ achieved in cancer patients following dosing at the recommended phase 2 dose [16].

While endoglin's role in canonical TGF- $\beta$ signaling is well documented [28], recent data indicate that BMP-9 and -10 are the important endoglin ligands that mediate Smad 1/5/8 phosphorylation needed for activation of primary EC [10, 29]. Our data corroborate that BMP-9 effectively stimulates Smad 1/5/ 8 phosphorylation (more than 30 fold induction), while TGF- $\beta 1$ only modestly stimulates Smad $2 / 3$ phosphorylation (approximately 5 fold induction). Our observation is consistent with the model suggesting that the BMP9-ALK1-Smad1/ $5 / 8$ and the TGF $\beta$-ALK5-Smad2/3 axes co-exist in parallel in primary human EC [10].
When HUVEC were pre-treated with TRC105, BMP-9induced Smad $1 / 5 / 8$ phosphorylation was inhibited by $50 \%$, even at the lowest dose of $0.2 \mu \mathrm{g} / \mathrm{ml}$ (Fig. 5b). In contrast, TGF- $\beta 1$-induced Smad 2/3 phosphorylation was less affected ( $<20 \%$ inhibition). It is well established that Smad $1 / 5 / 8$ signaling promotes EC activation. Therefore, the inhibition of this pathway exerted by TRC105 would lead to EC deactivation, contributing to the anti-angiogenic, anti-tumor function of TRC105.

In addition to blocking BMP9/Smad1/5/8 signaling, other mechanisms may be responsible for TRC105 anti-angiogenic function. For example, biomarker analyses from cancer patients treated with escalating doses of TRC105 revealed significant increases of soluble endoglin (sEnd) after TRC105 administration [30]. Kumar et al. proposed two mechanisms as to how TRC105 could induce sEnd shedding [31]. First, TRC105 could stabilize endoglin/MMP-14 complexes on the cell surface; second, TRC105 could induce MMP-14 gene expression to facilitate enzymatic cleavage of endoglin. In either event, sEnd would be released and serve as a trap for its ligand BMP-9, further diminishing the BMP9/Smad 1/5/8 pathway [32]. Another mechanism may involve the intracellular domain of endoglin. This domain contains important structural elements that serve as docking sites for multiple adaptor proteins, such as zyxin, zyxin-related protein 1 [33], $\beta$-arrestin2 [34], and GIPC [35]. It remains unclear how TRC105 binding to endoglin would affect these proteins and what role (s) the intracellular domain of endoglin plays in TRC105 function.

Clinically relevant doses of TRC105 were tested in these in vitro cell-based assays and could facilitate our understanding of the efficacy in vivo. Based on the superior effects of TRC105 and bevacizumab in HUVEC tube formation assays, the combination of both drugs has the potential to increase drug efficacy and reduce resistance. Currently, developing rationale-based combinations of multiple anti-angiogenic agents is a favored strategy to overcome resistance in the clinic [36]. Bevacizumab has been successfully added to chemo- and radiotherapy regimens and has significantly improved patient outcomes [37]. In the case of TRC105 and bevacizumab, with each drug targeting an independent pathway, more effective blockage of angiogenesis is expected. However, caution needs to be taken when determining drug dosing, relative ratio, frequency of administration, etc., to prevent the possible convergence of downstream effectors becoming exhausted or saturated.

In summary, we have demonstrated that the combination of TRC105 and bevacizumab led to greater inhibition in HUVEC functional assays, such as tube formation and migration, than either drug alone. We also explored Smad signaling and confirmed that diminished BMP9/Smad 1/5/8 signaling is a mechanism contributing to TRC105's anti-angiogenic, antitumor effect. The superior potency demonstrated by the drug 
combination advocates their co-administration in vivo as a therapeutic strategy.

Acknowledgments We would like to thank the staff from Light Microscopy Core Facility in Duke University Medical Center. This work was supported by a grant from Tracon Pharmaceuticals, Inc.

Conflict of interest Y Liu and H Tian have no conflicts to disclose. GC Blobe is a consultant/advisory board member and has received honorarium from Genentech and Roche. CP Theuer is the president and CEO of Tracon Pharmaceuticals, Inc. HI Hurwitz has received research funding from F Hoffman-La Roche, Amgen, Pfizer, Tracon Pharmaceuticals, Genentech, Sanofi, Morphotek and GSK. HI Hurwitz is a consultant/ advisory board member for GlaxoSmithKline, Novartis, Genentech, Roche, Sanofi, Regeneron, BMS, Bayer, and Tracon. AB Nixon has received research funding from Tracon Pharmaceuticals, F Hoffman-La Roche, Amgen, Pfizer and is a consultant/advisory board member for GlaxoSmithKline and Novartis.

Open Access This article is distributed under the terms of the Creative Commons Attribution License which permits any use, distribution, and reproduction in any medium, provided the original author(s) and the source are credited.

\section{References}

1. Carmeliet P, Jain RK (2000) Angiogenesis in cancer and other diseases. Nature 407(6801):249-257

2. Folkman J (2007) Angiogenesis: an organizing principle for drug discovery? Nat Rev 6(4):273-286

3. Hurwitz H, Fehrenbacher L, Novotny W, Cartwright T, Hainsworth J, Heim W, Berlin J, Baron A, Griffing S, Holmgren E, Ferrara N, Fyfe G, Rogers B, Ross R, Kabbinavar F (2004) Bevacizumab plus irinotecan, fluorouracil, and leucovorin for metastatic colorectal cancer. N Engl J Med 350(23):2335-2342

4. Van Meter ME, Kim ES (2010) Bevacizumab: current updates in treatment. Curr Opin Oncol 22(6):586-591. doi:10.1097/CCO. 0b013e32833edc0c

5. Jayson GC, Hicklin DJ, Ellis LM (2012) Antiangiogenic therapyevolving view based on clinical trial results. Nat Rev Clin Oncol 9(5): 297-303. doi:10.1038/nrclinonc. 2012.8

6. Samant RS, Shevde LA (2011) Recent advances in anti-angiogenic therapy of cancer. Oncotarget 2(3):122-134

7. Cheifetz S, Bellon T, Cales C, Vera S, Bernabeu C, Massague J, Letarte M (1992) Endoglin is a component of the transforming growth factor-beta receptor system in human endothelial cells. J Biol Chem 267(27):19027-19030

8. Burrows FJ, Derbyshire EJ, Tazzari PL, Amlot P, Gazdar AF, King SW, Letarte M, Vitetta ES, Thorpe PE (1995) Up-regulation of endoglin on vascular endothelial cells in human solid tumors: implications for diagnosis and therapy. Clin Cancer Res 1(12): $1623-1634$

9. Lebrin F, Goumans MJ, Jonker L, Carvalho RL, Valdimarsdottir G, Thorikay M, Mummery C, Arthur HM, ten Dijke P (2004) Endoglin promotes endothelial cell proliferation and TGF-beta/ALK1 signal transduction. EMBO J 23(20):4018-4028

10. Nolan-Stevaux O, Zhong W, Culp S, Shaffer K, Hoover J, Wickramasinghe D, Ruefli-Brasse A (2012) Endoglin requirement for BMP9 signaling in endothelial cells reveals new mechanism of action for selective anti-endoglin antibodies. PLoS ONE 7(12): e50920. doi:10.1371/journal.pone.0050920
11. Goumans MJ, Valdimarsdottir G, Itoh S, Rosendahl A, Sideras P, ten Dijke P (2002) Balancing the activation state of the endothelium via two distinct TGF-beta type I receptors. EMBO J 21(7):1743-1753

12. Dallas NA, Samuel S, Xia L, Fan F, Gray MJ, Lim SJ, Ellis LM (2008) Endoglin (CD105): a marker of tumor vasculature and potential target for therapy. Clin Cancer Res 14(7):1931-1937

13. Seon BK, Haruta Y, Matsuno F, Haba A, Takahashi N, She X, Harada N, Uneda S, Tsujie M, Tsujie T, Toi H, Tsai H (2010) Receptortargeted anticancer therapy. Immunol Res 46(1-3):189-191. doi:10. 1007/s12026-009-8131-8

14. Fonsatti E, Nicolay HJ, Altomonte M, Covre A, Maio M (2010) Targeting cancer vasculature via endoglin/CD105: a novel antibodybased diagnostic and therapeutic strategy in solid tumours. Cardiovasc Res 86(1):12-19. doi:10.1093/cvr/cvp332

15. Seon BK, Haba A, Matsuno F, Takahashi N, Tsujie M, She X, Harada N, Uneda S, Tsujie T, Toi H, Tsai H, Haruta Y (2011) Endoglintargeted cancer therapy. Curr Drug Deliv 8(1):135-143

16. Rosen LS, Hurwitz HI, Wong MK, Goldman J, Mendelson DS, Figg WD, Spencer S, Adams BJ, Alvarez D, Seon BK, Theuer CP, Leigh BR, Gordon MS (2012) A phase I first-in-human study of TRC105 (Anti-Endoglin Antibody) in patients with advanced cancer. Clin Cancer Res Off J Am Assoc Cancer Res 18(17):4820-4829. doi: 10.1158/1078-0432.CCR-12-0098

17. Liang CC, Park AY, Guan JL (2007) In vitro scratch assay: a convenient and inexpensive method for analysis of cell migration in vitro. Nat Protoc 2(2):329-333

18. Tsujie M, Tsujie T, Toi H, Uneda S, Shiozaki K, Tsai H, Seon BK (2008) Anti-tumor activity of an anti-endoglin monoclonal antibody is enhanced in immunocompetent mice. Int J Cancer 122(10):22662273. doi:10.1002/ijc. 23314

19. Scharpfenecker M, van Dinther M, Liu Z, van Bezooijen RL, Zhao Q, Pukac L, Lowik CW, ten Dijke P (2007) BMP-9 signals via ALK1 and inhibits bFGF-induced endothelial cell proliferation and VEGFstimulated angiogenesis. J Cell Sci 120(Pt 6):964-972. doi:10.1242/ jcs.002949

20. Haruta Y, Seon BK (1986) Distinct human leukemia-associated cell surface glycoprotein GP160 defined by monoclonal antibody SN6. Proc Natl Acad Sci U S A 83(20):7898-7902

21. Senger DR, Van de Water L, Brown LF, Nagy JA, Yeo KT, Yeo TK, Berse B, Jackman RW, Dvorak AM, Dvorak HF (1993) Vascular permeability factor (VPF, VEGF) in tumor biology. Cancer Metastasis Rev 12(3-4):303-324

22. Ferrara N, Gerber HP, LeCouter J (2003) The biology of VEGF and its receptors. Nat Med 9(6):669-676. doi:10.1038/nm0603-669

23. Anderberg C, Cunha SI, Zhai Z, Cortez E, Pardali E, Johnson JR, Franco M, Paez-Ribes M, Cordiner R, Fuxe J, Johansson BR, Goumans MJ, Casanovas O, ten Dijke P, Arthur HM, Pietras K (2013) Deficiency for endoglin in tumor vasculature weakens the endothelial barrier to metastatic dissemination. J Exp Med 210(3): 563-579. doi:10.1084/jem.20120662

24. Conley BA, Koleva R, Smith JD, Kacer D, Zhang D, Bernabeu C, Vary CP (2004) Endoglin controls cell migration and composition of focal adhesions: function of the cytosolic domain. J Biol Chem 279(26):27440-27449

25. Li C, Hampson IN, Hampson L, Kumar P, Bernabeu C, Kumar S (2000) CD105 antagonizes the inhibitory signaling of transforming growth factor betal on human vascular endothelial cells. FASEB J 14(1):55-64

26. Goumans MJ, Valdimarsdottir G, Itoh S, Lebrin F, Larsson J, Mummery C, Karlsson S, ten Dijke P (2003) Activin receptor-like kinase (ALK) 1 is an antagonistic mediator of lateral TGFbeta/ALK5 signaling. Mol Cell 12(4):817-828

27. Urbich C, Aicher A, Heeschen C, Dernbach E, Hofmann WK, Zeiher AM, Dimmeler S (2005) Soluble factors released by endothelial progenitor cells promote migration of endothelial cells and cardiac 
resident progenitor cells. J Mol Cell Cardiol 39(5):733-742. doi:10. 1016/j.yjmcc.2005.07.003

28. Blanco FJ, Santibanez JF, Guerrero-Esteo M, Langa C, Vary CP, Bernabeu C (2005) Interaction and functional interplay between endoglin and ALK-1, two components of the endothelial transforming growth factor-beta receptor complex. J Cell Physiol 204(2):574-584. doi:10.1002/jcp.20311

29. Alt A, Miguel-Romero L, Donderis J, Aristorena M, Blanco FJ, Round A, Rubio V, Bernabeu C, Marina A (2012) Structural and functional insights into endoglin ligand recognition and binding. PLoS ONE 7(2):e29948. doi:10.1371/journal.pone.0029948

30. Liu Y, Starr MD, Brady JC, Dellinger A, Pang H, Adams B, Theuer CP, Lee NY, Hurwitz HI, Nixon AB (2014) Modulation of circulating protein biomarkers following TRC105 (anti-endoglin antibody) treatment in patients with advanced cancer. Cancer Med. doi:10.1002/cam4.207

31. Kumar S, Pan CC, Bloodworth JC, Nixon A, Theuer C, Hoyt DG, Lee NY (2013) Antibody-directed coupling of endoglin and MMP14 is a key mechanism for endoglin shedding and deregulation of TGF-beta signaling. Oncogene. doi:10.1038/onc.2013.386

32. Castonguay R, Werner ED, Matthews RG, Presman E, Mulivor AW, Solban N, Sako D, Pearsall RS, Underwood KW, Seehra J, Kumar R, Grinberg AV (2011) Soluble endoglin specifically binds bone morphogenetic proteins 9 and 10 via its orphan domain, inhibits blood vessel formation, and suppresses tumor growth. J Biol Chem 286(34):30034-30046. doi:10.1074/jbc.M111.260133

33. Sanz-Rodriguez F, Guerrero-Esteo M, Botella LM, Banville D, Vary CP, Bernabeu C (2004) Endoglin regulates cytoskeletal organization through binding to ZRP-1, a member of the Lim family of proteins. J Biol Chem 279(31):32858-32868. doi:10. 1074/jbc.M400843200

34. Lee NY, Blobe GC (2007) The interaction of endoglin with betaarrestin2 regulates transforming growth factor-beta-mediated ERK activation and migration in endothelial cells. J Biol Chem 282(29): 21507-21517. doi:10.1074/jbc.M700176200

35. Lee NY, Ray B, How T, Blobe GC (2008) Endoglin promotes transforming growth factor beta-mediated Smad 1/5/8 signaling and inhibits endothelial cell migration through its association with GIPC. J Biol Chem 283(47):32527-32533. doi:10.1074/jbc.M803059200

36. Shojaei F (2012) Anti-angiogenesis therapy in cancer: current challenges and future perspectives. Cancer Lett 320(2):130-137. doi:10. 1016/j.canlet.2012.03.008

37. Abdollahi A, Folkman J (2010) Evading tumor evasion: current concepts and perspectives of anti-angiogenic cancer therapy. Drug Resist Updat 13(1-2):16-28. doi:10.1016/j.drup.2009.12.001 